\title{
Микитюк Юрий Васильевич
}

ОРГАНИЗАЦИЯ ДЕЯТЕЛЬНОСТИ ВНУТРЕННИХ ВОЙСК МВД УКРАИНЫ (1991-2014 ГОДЫ)

В статье рассмотрены вопросы формирования и развития внутренних войск в структуре Министерства внутренних дел Украины в период с 1991 года по 2014 год. Детально охарактеризованы специфика служебно-боевой деятельности этого воинского формирования с правоохранительными функциями, его основные задачи и функции на различных этапах становления украинской государственности и правоохранительной системы. Историкоправовой экскурс позволил выявить предпосылки и понять причины трансформации данного органа правопорядка в воинское формирование, используемое в "антитеррористической операции" на юго-востоке Украины и специальных операциях против оппозиционных сил и гражданской активности.

Адрес статьи: www.gramota.net/materials/9/2019/1/15.htm

\section{Источник}

\section{Манускрипт}

Тамбов: Грамота, 2019. Том 12. Выпуск 1. С. 72-75. ISSN 2618-9690.

Адрес журнала: www.gramota.net/editions/9.html

Содержание данного номера журнала: www.gramota.net/materials/9/2019/1/

\section{() Издательство "Грамота"}

Информация о возможности публикации статей в журнале размещена на Интернет сайте издательства: www.gramota.net Вопросы, связанные с публикациями научных материалов, редакция просит направлять на адрес: hist@gramota.net 
4. Aldgate A., Richards J. Britain Can Take It: British Cinema in the Second World War. Edinburgh: Edinburgh University Press, 1994. 342 p.

5. Calder A. The Peoples' War: Britain 1939-1945. L.: Pimlico, 1992. 672 p.

6. Cardiff D., Scannell P. Good Luck, War Workers! Class, Politics and Entertainment in Wartime Broadcasting // Popular Culture and Social Relations / ed. by T. Bennett, C. Mercer, J. Wollacott. Milton Keynes: Open University Press, 1986. P. 93-116.

7. Churchill Forms Wartime Coalition Government [Электронный pecypc] // Information Britain. URL: http://www.informationbritain.co.uk/famdates.php?id=354 (дата обращения: 10.10.2018).

8. Churchill W. We Shall Fight on the Beaches [Электронный ресурc] // International Churchill Society. URL: https://winstonchurchill. org/resources/speeches/1940-the-finest-hour/we-shall-fight-on-the-beaches (дата обращения: 10.10.2018).

9. Doherty M. A. Nazi Wireless Propaganda. Lord Haw-Haw and British Public Opinion in the Second World War. Edinburgh: University Press, 2000. 208 p.

10. Hickman T. What Did You Do in the War, Auntie? The BBC at War 1939-45. L.: BBC Publications, 1996. 224 p.

11. Marwick A. Class: Image and Reality. L.: Macmillan, 1990. 435 p.

12. Rothermere: Hurrah to the Blackshirts! [Электронный ресурс]. URL: https://commons.wikimedia.org/wiki/File: Rothermere_Hurrah_for_the_Blackshirts.jpg (дата обращения: 10.10.2018).

13. Scannell P., Cardiff D. Radio in World War II // Popular Culture. Milton Keynes: Open University Press, 1981. P. 31-78.

14. Williams K. Get Me a Murder a Day! L.: Arnold, 1998. 287 p.

15. Yass M. This Is Your War: Home Front Propaganda in the Second World War. L.: HMSO, 1983. 62 p.

\title{
THE BRITISH MEDIA DURING THE SECOND WORLD WAR: FEATURES OF FUNCTIONING
}

\author{
Malakhovskaya Vera Vladimirovna, Ph. D. in Philology \\ Malakhovskii Aleksei Kimovich, Ph. D. in History, Associate Professor \\ Peoples' Friendship University of Russia, Moscow \\ malakhovskaya-vv@pfur.ru; malakhovskiy_ak@pfur.ru
}

The article presents an analysis of the information activity of the British media during the Second World War. The purpose of the research is to study the features of the government agencies interaction with all the media channels. The novelty of the work is in the fact that the authors carry out a comprehensive analysis of the activity of the coalition government and the Ministry of Information in relation to the British media on the basis of attracting original material. The paper determines the evolution stages of the information policy of the government circles and ascertains that they managed to overcome difficulties and to establish effective propaganda during the war.

Key words and phrases: British media; British ruling circles; "press barons"; W. Churchill's coalition government; Ministry of Information; propaganda campaigns; censorship; BBC radio corporation; broadcasting network; British press; news agencies; cinematography.

УДК 93/94; 351.746:930.23(477)

https://doi.org/10.30853/manuscript.2019.1.15

Дата поступления рукописи: 12.11.2018

В статье рассмотрены вопросы формирования и развития внутренних войск в структуре Министерства внутренних дел Украины в период с 1991 года по 2014 год. Детально охарактеризовань специфика служебнобоевой деятельности этого воинского формирования с правоохранительными функциями, его основнье задачи и функции на различных этапах становления украинской государственности и правоохранительной системы. Историко-правовой экскурс позволил выявить предпосылки и понять причины трансформации данного органа правопорядка в воинское формирование, используемое в «антитеррористической операчии» на юго-востоке Украины и специальных операциях против оппозиционных сил и гражданской активности.

Ключевые слова и фразы: внутренние войска; воинское формирование; историко-правовое исследование; МВД Украины; обеспечение общественной безопасности; охрана общественного порядка; правоохранительные функции.

Микитюк Юрий Васильевич, к.и.н.

Крымский филиал Краснодарского университета

Министерства внутренних дел Российской Федерации, г. Симферополь

kf.krdu@mvd.ru

\section{ОРГАНИЗАЦИЯ ДЕЯТЕЛЬНОСТИ ВНУТРЕННИХ ВОЙСК МВД УКРАИНЫ (1991-2014 ГОДЫ)}

Внутренние войска в СССР и их преемники в большинстве стран постсоветского пространства представлены воинскими формированиями, деятельность которых организована по армейскому принципу, а основными задачами являются охрана общественного порядка, обеспечение конституционного строя, защита прав и свобод граждан. Значительная часть положений советского законодательства, касающихся деятельности внутренних войск, с определенными изменениями и дополнениями были реципированы входившими в состав СССР республиками, в том числе Украиной [11, с. 12-16].

Задача исследования состоит в том, чтобы охарактеризовать основные этапы развития внутренних войск МВД Украины, опираясь на историко-правовой анализ организационно-правовых основ их деятельности. 
Научная новизна и практическая ценность статьи обусловлены рассмотрением проблем организации деятельности внутренних войск на конкретном этапе развития украинской государственности, в первую очередь, через призму соблюдения прав и свобод человека и интересов общества.

Несмотря на значительный интерес ученых и практиков к деятельности данного органа правопорядка, историко-правовой анализ основных этапов формирования и развития внутренних войск МВД Украины в период с 1991 по 2014 год отдельно не проводился, а осуществлялся фрагментарно либо поверхностно при рассмотрении более широких вопросов. Соответственно, актуализируется необходимость проведения монографического, поэтапного исследования организации деятельности внутренних войск в данный период. При этом следует указать, что выбор временного отрезка для изыскания обусловлен: во-первых, распадом СССР и началом формирования государственности и правоохранительных систем в бывших союзных республиках с 1991 г.; во-вторых, неоднократными попытками внедрить в украинское правовое поле и сектор безопасности и обороны европейские модели функционирования правоохранительных систем; в-третьих, ликвидацией внутренних войск после событий «евромайдана» и радикальным изменением Западом политического курса Украины в 2014 г.

Согласно одному из первых нормативных актов парламента постсоветской Украины все воинские формирования, дислоцированные на территории республики, были переподчинены Верховной Раде Украины [4]. В августе 1991 г. все воинские части МВД СССР и их органы управления, находившиеся в республике, были переведены под юрисдикцию Украины [8].

В ноябре 1991 г. была начата работа по созданию воинского формирования с правоохранительными функциями и органа управления ими в составе МВД [9]. Первично в его задачи входили: охрана и оборона важных государственных объектов, исправительно-трудовых и лечебно-трудовых учреждений, объектов материально-технического и воинского обеспечения МВД; сопровождение специальных грузов; осуществление пропускного режима на охраняемых объектах; конвоирование арестованных и осужденных; охрана подсудимых во время судебного процесса; преследование и задержание арестованных и осужденных лиц, сбежавших из-под стражи; участие в надзоре за осужденными и лицами, содержащимися в лечебно-трудовых профилакториях, выполнение поручений администрации этих учреждений по обеспечению внутреннего порядка; оказание помощи милиции в охране общественного порядка; участие в ликвидации последствий чрезвычайных ситуаций на охраняемых объектах [5]. В свою очередь, функции Главного управления осуществлялись по направлениям: организационно-правовое обеспечение; учебно-методическая, режимная и кадровая работа; тыловое (материальное, техническое, финансовое) обеспечение; контроль и аналитика; международное сотрудничество [11, с. 8-9]. А структура в регионах была представлена Восточным, Западным, Крымским, Северным, Центральным, Южным территориальными командованиями и частями прямого подчинения.

Что касается подготовки квалифицированных специалистов для внутренних войск, то в январе 1992 г. было образовано Харьковское высшее военное училище Национальной гвардии Украины (с июля 1995 г. - Военный институт Национальной гвардии Украины). В конце 1990-х образовательная организация получила название Военный институт внутренних войск МВД Украины, а уже в апреле 2006 г. была реорганизована в Академию. Помимо подготовки военнослужащих на 4 факультетах (командно-штабной, инженерно- технический, гуманитарный, экономики и менеджмента), осуществлялось обучение студентов по очной и заочной формам обучения на контрактной основе. В начале 2000 -х годов в вузе идет активная разработка и апробация научноисследовательских и опытно-конструкторских работ, в том числе совместно с научно-педагогическими сотрудниками других образовательных организаций системы МВД Украины и Службы безопасности Украины. В частности, в рамках работы адъюнктуры и специализированного ученого совета осуществлялась подготовка и защита диссертаций на соискание научных степеней по специальностям 21.07.05 - служебно-боевая деятельность сил охраны правопорядка; 20.02.14 - вооружение и военная техника. Впрочем, мониторинг и сопровождение нормативно-правовых основ деятельности внутренних войск остались без внимания научной общественности.

Безусловно, при осуществлении поставленных задач, выполнении возложенных на военнослужащих внутренних войск обязанностей и реализации предоставленных им прав возникали обстоятельства, при которых они могли применять (использовать) меры физического воздействия, специальные средства, боевую технику и огнестрельное оружие. Тем не менее законодатель предоставил военнослужащим внутренних войск право на использование и применение силы, а также гарантии их личной безопасности исключительно на основаниях и в порядке, предусмотренном Законом Украины «О милиции», воинскими уставами Вооруженных Сил и другими актами законодательства. Наличие бланкетных и отсылочных норм права не могло не отразиться на боеспособности данного воинского формирования, различном толковании положений законодательных актов командным составом и рассогласованности действий личного состава при усложнении оперативной обстановки.

В начале 2000-х годов назначение внутренних войск заключалось в реализации совместно с другими уполномоченными субъектами двух основных правоохранительных функций: во-первых, защита прав и свобод граждан, охрана правопорядка; во-вторых, защита государства и обеспечение его безопасности. Именно поэтому руководством государства неоднократно поднимались вопросы о преобразовании внутренних войск в демилитаризированное формирование с правоохранительными функциями [10] (с целью освобождения МВД от выполнения несвойственных задач). Ключевые направления реформирования базировались на необходимости поддержания адекватной правоохранительной потенции и должны были обеспечивать: закон и порядок; защиту важных государственных объектов; противодействие терроризму, экстремизму и различным формам сепаратизма; безопасность при проведении судебных процессов и сопровождении особо важных грузов; силовую поддержку уполномоченных органов при проведении специальных операций в случае осложнения оперативной обстановки; оказание помощи уполномоченным органам при реагировании на чрезвычайные ситуации 
природного и техногенного характера и т.п. Кроме этого, предполагалось, что внутренние войска будут принимать участие в миротворческих операциях, а после объявления войны - усиливать Вооруженные силы для выполнения задач территориальной обороны, участвовать в нейтрализации угроз военного характера.

Но указанное направление развития внутренних войск оказалось нежизнеспособным. А их преобразование в сугубо воинское формирование, на которое возложены задания в сфере обеспечения внутренней безопасности, требующие постоянной оперативной готовности и повышенной мобильности, виделось более перспективным [6]. Другими словами, в силу мультифункциональности и разноплановости своей деятельности внутренние войска должны были предупреждать и реагировать на широкий круг источников внутренних и внешних угроз национальной безопасности. Тем не менее в целом попытки реформирования украинских внутренних войск можно охарактеризовать как навязчивые идеи интеграции в структуры блока НАТО и проецирования моделей организации деятельности органов правопорядка стран Европейского союза. Но такое «совершенствование» осуществлялось без учета накопленного опыта, национальных традиций, менталитета, уровней правового и материально-технического обеспечения правоохранительных органов Украины, а также подготовки их личного состава.

Очевидно, что большинство задач внутренних войск должно было выполняться в тесном взаимодействии с воинскими формированиями, правоохранительными и другими государственными органами, при этом внутренние войска в основном использовались как вспомогательная сила. В то же время разноплановый характер их совместной деятельности на фоне чрезмерной зарегулированности множеством ведомственных инструкций, наставлений и положений часто становился преградой для успешного выполнения коалиционных задач, достижения общей цели.

Следует указать, что в украинский парламент неоднократно вносились законодательные инициативы различных субъектов нормотворчества, касающиеся изменений организационных и правовых основ деятельности внутренних войск, их ведомственной принадлежности и подотчетности [12, с. 249-250]. Например, альтернативным действующему Закону Украины «О Национальной гвардии Украины» был одноименный законопроект [7], которым предусматривалось, что Национальная гвардия должна стать правоохранительным органом специального назначения, на который возложена защита суверенитета Украины, ее территориальной целостности, жизни и личного достоинства граждан, их конституционных прав и свобод от преступных посягательств и предупреждение других антиобщественных действий. К ее основным задачам планировалось отнести: защиту конституционного строя, целостности ее территории от попыток изменить их насильственным путем; охрану и оборону важных государственных объектов, в том числе атомных электростанций, дипломатических и консульских представительств иностранных государств на территории Украины; участие в поддержании режима чрезвычайного положения, ликвидации последствий чрезвычайных ситуаций техногенного и природного характера; сопровождение специальных грузов; участие в охране общественного порядка, борьбе с преступностью и терроризмом; оказание помощи Государственной пограничной службе Украины в задержании нарушителей государственной границы силами частей, дислоцированных в приграничных районах; участие в боевых действиях по отпору вооруженной агрессии.

В то же время новеллой этого нормативного акта должно было стать закрепление принципа подотчетности и подконтрольности парламенту. При этом данным правоохранительным органом специального назначения должен был управлять командующий, которого назначала бы Верховная Рада по представлению главы государства на пятилетний срок (не более двух сроков подряд). Что касается роли главы государства в управлении этим сугубо воинским формированием, то она ограничивалась: назначением заместителей командующего Национальной гвардии по представлению ее командующего; утверждением плана ее дислокации (по согласованию с Кабинетом Министров), положения о прохождении службы в Национальной гвардии, положения и персонального состава Военного совета Национальной гвардии. Таким образом, последняя должна была выйти из состава МВД и подчинения Министра [Там же]. Впрочем, создание нового самостоятельного воинского формирования выбивалось из общей стратегии реформирования сектора обороны и безопасности, а его введение под контроль и отчет парламенту выглядело нерациональным. К тому же контрольно-надзорная система и так была достаточно разветвленной и многовекторной [1, с. 94-98].

Итак, в начале 2010-х годов противоречия и пробелы в Законе Украины «О внутренних войсках Министерства внутренних дел Украины» стали серьезным препятствием для надлежащего правоприменения. Это было связано с тем, что закон был принят еще в 1992 г., морально устарел, вступал в разногласие с другими нормативными правовыми актами, а новые угрозы и вызовы национальной и общественной безопасности диктовали необходимость радикальных реформ по организации деятельности органов безопасности и правопорядка. Как следствие, низкая эффективность служебно-боевой деятельности внутренних войск, несогласованность их действий с милицией, усиленные бездействием высшего политического руководства страны, были наглядно продемонстрированы во время государственного переворота на Украине (ноябрь 2013 г. - февраль 2014 г.).

Безусловно, деятельность внутренних войск и подобных воинских формирований, в отличие от других органов правопорядка, имеет определенную специфику, прежде всего, обусловленную их пребыванием в структуре МВД. Как следствие, особенности деятельности и приоритетные задачи Министерства проецируется на соответствующих направлениях деятельности внутренних войск. Считаем, что данное воинское формирование с правоохранительными функциями является основной силовой составляющей Министерства в сфере обеспечения общественной безопасности и осуществляет правоохранительную деятельность формами и методами, отличными от Вооруженных сил.

Таким образом, полярные подходы к вопросам оптимизации деятельности внутренних войск, несамостоятельность, политизированность и ангажированность их командования, существенные просчеты в управленческой 
деятельности, недостатки организационного, правового и материально-технического обеспечения в конечном итоге привели к низкому уровню боеготовности и боеспособности имеющихся сил и средств, а в результате событий «революции достоинства» личный состав внутренних войск был полностью деморализован и дискредитирован. После антиконституционной смены власти на Украине в марте 2014 г. вместо внутренних войск была создана Национальная гвардия, с одновременным смещением акцентов в ее деятельности с защиты прав и свобод граждан, законных интересов общества [3, с. 17-20] на выполнение узкокорпоративных заданий политических элит по борьбе с оппозиционными силами, противодействию позитивной гражданской активности и ведению боевых действий против собственного населения [2, с. 74-75] в качестве карательно-репрессивного органа с широким перечнем дискреционных полномочий, личной армии министра внутренних дел.

Проведенный историко-правовой анализ организации деятельности внутренних войск МВД Украины в 1991-2014 годы убедительно свидетельствует о том, что развитие правового демократического государства и институтов гражданского общества неразрывно связаны с совершенствованием механизма защиты прав и свобод граждан и законных интересов общества от противоправных посягательств. Ведущую роль в таком механизме должны играть именно органы безопасности и правопорядка, в том числе воинские формирования с правоохранительными функциями (внутренние войска, войска карабинеров, национальная или гражданская гвардии, жандармерия и др.). В результате проводимых реформ задачи и функции внутренних войск менялись вместе с угрозами национальной безопасности Украины, пройдя путь от войск внутренней и конвойной охраны (1992) до Национальной гвардии (2014). Но при возникновении чрезвычайных ситуаций внутренние войска оказались неспособными своевременно среагировать и локализовать их последствия.

Считаем, что с учетом ошибок и просчетов в организации деятельности аналогичных воинских формирований с правоохранительными функциями иностранных государств результаты проведенного исследования могут быть использованы при дальнейшей оптимизации организационных и правовых основ деятельности войск национальной гвардии Российской Федерации.

\title{
Список источников
}

1. Бокий А. Н., Микитенко В. В. Контроль и надзор за служебно-боевой деятельностью сил охраны правопорядка в Украине // Вестник Казанского юридического института МВД России. 2013. № 4 (14). С. $92-99$.

2. Буткевич С. А. Административно-правовой режим антитеррористической операции в Украине: проблемы теории и практики // Вестник Краснодарского университета МВД России. 2015. № 1 (27). С. 72-76.

3. Буткевич С. А. Законодательный и доктринальный подходы к проблеме противодействия терроризму // Противодействие экстремизму и терроризму в Крымском федеральном округе: проблемы теории и практики: монография / отв. ред. С. А. Буткевич. Симферополь: КФ КрУ МВД России, 2015. С. 5-31.

4. О военных формированиях на Украине: Постановление Верховной Рады Украины от 24 августа 1991 г. № 1431-XII // Ведомости Верховной Рады Украины. 1991. № 38. Ст. 506.

5. О войсках внутренней и конвойной охраны: Закон Украины от 26 марта 1992 г. № 2235-ХІІ // Ведомости Верховной Рады Украины. 1992. № 29. Ст. 397.

6. О Концепции развития внутренних войск МВД Украины на период до 2015 года: Приказ Министерства внутренних дел Украины от 29 ноября 2006 г. № 1167. К., 2006. 9 с.

7. О Национальной гвардии Украины [Электронный ресурс]: проект Закона Украины от 12 марта 2014 г. № 4393-1. URL: http://w1.c1.rada.gov.ua/pls/zweb2/webproc4_1?pf3511=50134 (дата обращения: 11.11.2018).

8. О подчинении Украине внутренних войск, которые дислоцируются на ее территории: Указ Президиума Верховной Рады Украины от 30 августа 1991 г. № 1465-XII // Ведомости Верховной Рады Украины. 1991. № 44. Ст. 592.

9. О создании в системе Министерства внутренних дел Украины войск внутренней и конвойной службы: Распоряжение Председателя Верховной Рады Украины от 29 ноября 1991 г. № 1860-XII // Ведомости Верховной Рады Украины. 1992. № 5. Ст. 36 .

10. По вопросу о преобразовании внутренних войск Министерства внутренних дел Украины в невоинское формирование: Указ Президента Украины от 18 августа 2003 г. № 863/2003 // Официальный вестник Украины. 2003. № 34. Ст. 1813.

11. Савочкіна Д. О. Адміністративно-правове забезпечення діяльності Національної гвардії України: дисс. ... к.ю.н. Дніпропетровськ, 2015. 214 с.

12. Яровий С. А. Внутрішні війська Міністерства внутрішніх справ України: стан і шляхи реформування // Південноукраїнський правничий часопис. 2012. № 4. С. 247-251.

\section{ORGANIZATION OF ACTIVITY OF THE INTERIOR TROOPS \\ OF THE MINISTRY OF INTERIOR OF UKRAINE (1991-2014)}

\author{
Mikityuk Yurii Vasil'evich, Ph. D. in History \\ Krasnodar University of the Ministry of Internal Affairs of the Russian Federation (Branch) in Crimea, Simferopol \\ kf.krdu@mvd.ru
}

The article examines the problems of the formation and development of the interior troops in the structure of the Ministry of Interior of Ukraine in the period from 1991 till 2014. The author characterizes in detail the peculiarities of the combat activity of this military unit with law enforcement functions, describes its basic tasks and functions at different stages of the formation of the Ukrainian statehood and law-enforcement system. Historical and legal excursus allowed the author to identify the premises and to reveal the causes of the transformation of this law enforcement body into a military unit used in the "anti-terrorist operation" in the south-east of Ukraine and in special operations against oppositional forces and civil rights activists.

Key words and phrases: interior troops; military unit; historical and legal study; Ministry of Interior of Ukraine; public security maintenance; public order enforcement; law enforcement functions. 